negotiating their budgets. The recommendations will have to include adequate provision for equipment costs, unlike the current situation where, owing to financial constraints, no replacement policy exists and a great deal of equipment is provided from charitable donations. We have estimated the equipment shortfall within only the neonatal service, but it is likely that a similar situation exists in other specialties. Although not all of these disciplines depend as heavily on equipment for their day to day work as does the neonatal service, such shortfalls inevitably detract from optimal clinical care.

As far as government is concerned, the setting up of budget holding units should parallel industrial privatisation, with current shortfalls in provision of equipment being likened to outstanding debts. Writing off these debts using government funds would prevent budget holders having to cope with an inherited chronic shortfall in the provision of appropriate equipment, which would adversely affect their operating costs. The government clearly thought that such a move was vital before it sold off Rover. To correct all such deficiencies before introducing new contracts would require a large injection of capital, but this measure might mean the difference between success and failure for a marketplace economy for health services

We thank all 17 perinatal units in the Trent region who cooperated with this study. Funding was provided by the regional health authority. ACF is supported by the Spastics Society.

\section{Appendix}

The following equipment (No of items) is recommended by the British Paediatrics Association and British Association of Perinatal Paediatrics to be available for each baby receiving intensive care:

Intensive care incubator or unit with overhead heating (1) Respiratory or apnoea monitor (1)

Intravascular blood pressure transducer or surface blood pressure recorder $(1)$

Transcutaneous $\mathrm{Po}_{2}$ monitor or intravascular oxygen transducer (1)

Transcutaneous $\mathrm{PCO}_{2}$ monitor (1)

Syringe pumps (2)

Infusion pumps (2)

Ventilator (1)

Continuous temperature monitor $(1)$

Phototherapy unit (1)

Ambient oxygen monitor (1)

Facilities for frequent blood gas analysis using micromethods

Facilities for frequent biochemical analysis including glucose, bilirubin, and electrolytes by micromethods

Access to ultrasound equipment for visualisation of organs such as the brain

Access to equipment for radiological examination

1 Ryan S, Sics A, Congdon P. Cost of neonatal care. Arch Dis Child 1988;63 303-6.

Royal College of Physicians of London. Medical care of the newborn in England and Wales. London: Royal College of Physicians, 1988.

British Paediatric Association, British Association of Perinatal Paediatrics. Categories of babies requiring neonatal care. London: British Paediatric Categones of babies requiring neonatal care. London: British
Association/British Association of Perinatal Paediatrics, 1984.

4 Field DJ, Hodges S, Mason E, Burton P, Yates J, Wale S. The demand for neonatal intensive care. Br Med f 1989;299:1305-8.

(Accepted 15 May 1990)
Physical Education

Association Research

Centre and Schools of Education and

Postgraduate Medicine, University of Exeter, Exeter EX1 2LU

Neil Armstrong, PHD, senior lecturer

John Balding, MMEDSCI, senior lecturer

Peter Gentle, FFCM, honorary

senior lecturer

Brian Kirby, FRCP, senior lecturer

Correspondence to: Dr Neil Armstrong, Physical Education Association Research Centre, School of Education, University of Exeter, Excter EX1 2LU.

BrMed f 1990;301:203-5

\title{
Patterns of physical activity among 11 to 16 year old British children
}

\author{
Neil Armstrong, John Balding, Peter Gentle, Brian Kirby
}

\begin{abstract}
Objective-To examine the patterns of physical activity among British schoolchildren aged 11 to 16 and to assess whether the children experience the intensity and duration of physical activity that are believed to stress the cardiopulmonary system appropriately.
\end{abstract}

Design-Cross sectional study of a sample of children drawn from a larger survey of coronary risk factors in children. Continuous monitoring of heart rate for 12 hour periods on three school days and one Saturday.

Setting - Two communities in Devon.

Subjects - 266 Children (163 girls, 103 boys) aged 11 to 16 randomly selected from a sample of 707 children.

Main outcome measures-Percentage of time and number of sustained periods in which heart rate was $>139$ beats $/ \mathrm{min}$. Anthropometric measures and external assessment of sexual maturity with Tanner's indices.

Results - The boys had heart rates $>139$ beats/ min for a significantly higher percentage of time than the girls $(p<0.01)$ during the weekday $(6.2 \% v 4.3 \%)$ and the Saturday $(5.6 \% v 2.6 \%)$. The boys had significantly more five and $\mathbf{1 0}$ minute periods with heart rates $>139$ beats/min than the girls during the Saturday and weekdays and more 20 minute periods during the weekdays. 84 Girls and 37 boys had no 10 minute period with a heart rate $>139$ beats/min during the three weekdays and 112 girls and 65 boys had no such 10 minute period during the Saturday. No significant relation was detected in either sex between the amount or habitual physical activity (heart rate) and skinfold thickness or maturity group.

Conclusions-British children have surprisingly low levels of habitual physical activity, and many children seldom undertake the volume of physical activity believed to benefit the cardiopulmonary system. Boys are more active than girls. The pubertal stage of development or body fatness, or both, do not seem to be sensitive indicators of physical activity in either girls or boys.

\section{Introduction}

Simons-Morton et al recently reviewed published recommendations for physical activity for children and concluded that appropriate physical activity entailed dynamic movement of large muscle groups for 20 minutes or longer, three or more times a week, at an intensity eliciting heart rates $\geqslant 140$ beats/min (roughly $70 \%$ of the maximal heart rate). ${ }^{1}$ Whether British children regularly undertake this degree of physical activity was unknown. We therefore examined the patterns of physical activity among British schoolchildren aged 11 to 16 and assessed the amount of appropriate physical activity.

\section{Subjects and methods}

We invited all children in state school years seven to 10 in two well defined communities in Devon to participate in a research project on the prevalence of coronary risk factors in children. The two localities surveyed were broadly comparable with much of 
southern England. ${ }^{2}$ Written informed consent was obtained from 707 children (42\% of those eligible) and their parents. In an attempt to detect sample bias we compared the heights and weights of the children who participated in the study with those of the children who declined to participate. Analysis by $t$ test showed no significant difference $(p>0.05)$ in either height or weight in any year group for either sex. We randomly selected 266 of the children to have their patterns of physical activity monitored and collected data throughout one school year (September to July).

\section{PHYSICAL CHARACTERISTICS}

Height, weight, and skinfold thickness over the triceps and the subscapular region were measured according to the techniques described by Weiner and Lourie. ${ }^{3}$ All skinfold measurements were carried out by the same experienced observer, and the sum of skinfold thicknesses was obtained by adding the scores for the triceps and the subscapular region. The external sexual maturity of 219 children was assessed visually using the indices developed by Tanner. ${ }^{4}$

\section{ASSESSMENT OF PHYSICAL ACTIVITY}

The volume (frequency, intensity, and duration) of physical activity was estimated from continuous monitoring of the heart rate over three weekdays and one Saturday. This is not a direct measure of physical

TABLE I-Physical characteristics of children monitored for three weekdays. Values are means (SDs)

\begin{tabular}{lcc}
\hline & Boys $(\mathrm{n}=103)$ & Girls $(\mathrm{n}=163)$ \\
\hline Age (years) & $13 \cdot 1(1 \cdot 2)$ & $13 \cdot 1(1 \cdot 3)$ \\
Height $(\mathrm{m})$ & $1 \cdot 57(0 \cdot 11)$ & $1 \cdot 56(0 \cdot 10)$ \\
Weight $(\mathrm{kg})$ & $47 \cdot 5(11 \cdot 2)$ & $46 \cdot 9(9 \cdot 4)$ \\
Sum of skinfold thicknesses $(\mathrm{mm})$ & $19 \cdot 7(8 \cdot 9)$ & $25 \cdot 7(10 \cdot 5)$ \\
\hline
\end{tabular}

TABLE II -Number of sustained periods with heart rate $>139$ beats $/$ min recorded during continuous monitoring of schoolchildren aged 11 to 16. Values are numbers (percentages) of children

\begin{tabular}{lccccc}
\hline & \multicolumn{2}{c}{ Three weekdays } & & \multicolumn{2}{c}{ Saturday } \\
\cline { 2 - 3 } \cline { 5 - 6 } Period & Boys $(\mathbf{n}=103)$ & Girls $(\mathbf{n}=163)$ & & Boys $(\mathbf{n}=92)$ & Girls $(\mathbf{n}=120)$ \\
\hline 5 Min: & & & & & \\
0 & $5(4 \cdot 9)$ & $23(14 \cdot 1)$ & & $43(46 \cdot 7)$ & $77(64 \cdot 2)$ \\
1 & $14(13 \cdot 6)$ & $26(16 \cdot 0)$ & & $18(19 \cdot 6)$ & $20(16 \cdot 7)$ \\
2 & $12(11 \cdot 7)$ & $27(16 \cdot 6)$ & & $3(3 \cdot 3)$ & $9(7 \cdot 5)$ \\
$\geqslant 3$ & $72(69 \cdot 9)$ & $87(53 \cdot 4)$ & & $28(30 \cdot 4)$ & $14(11 \cdot 7)$ \\
10 Min: & & & & & \\
0 & $37(35 \cdot 9)$ & $84(51 \cdot 5)$ & & $65(70 \cdot 7)$ & $112(93 \cdot 3)$ \\
1 & $27(26 \cdot 2)$ & $34(20 \cdot 9)$ & & $9(9 \cdot 8)$ & $5(4 \cdot 2)$ \\
2 & $15(14 \cdot 6)$ & $25(15 \cdot 3)$ & & $9(9 \cdot 8)$ & $3(2 \cdot 5)$ \\
$\geqslant 3$ & $24(23 \cdot 3)$ & $20(12 \cdot 3)$ & & $9(9 \cdot 8)$ & \\
20 Min: & & & & & \\
0 & $79(76 \cdot 7)$ & $143(87 \cdot 7)$ & & $81(88 \cdot 0)$ & $116(96 \cdot 7)$ \\
1 & $15(14 \cdot 6)$ & $17(10 \cdot 4)$ & & $9(9 \cdot 8)$ & $3(2 \cdot 5)$ \\
2 & $5(4 \cdot 9)$ & $2(1 \cdot 2)$ & & $1(1 \cdot 1)$ & $1(0 \cdot 8)$ \\
$\geqslant 3$ & $4(3 \cdot 9)$ & $1(0 \cdot 6)$ & & $1(1 \cdot 1)$ & \\
\hline
\end{tabular}

TABLE III-Characteristics of children participating in three day monitoring according to sexual maturity. Values are means $(S D s)$

\begin{tabular}{|c|c|c|c|c|c|}
\hline & \multicolumn{5}{|c|}{ Maturity group } \\
\hline & 1 & 2 & 3 & 4 & 5 \\
\hline \multicolumn{6}{|c|}{ Boys } \\
\hline & $(n=10)$ & $(\mathbf{n}=37)$ & $(\mathrm{n}=17)$ & $(n=15)$ & $(\mathrm{n}=10)$ \\
\hline Age (years) & $11 \cdot 8(0.4)$ & $12 \cdot 5(0 \cdot 9)$ & $13 \cdot 3(1 \cdot 0)$ & $14 \cdot 1(0.9)$ & $13 \cdot 7(1 \cdot 2)$ \\
\hline Height (m) & $1.45(0.10)$ & $1.51(0.07)$ & $1.58(0.06)$ & $1.68(0.06)$ & $1.68(0 \cdot 10)$ \\
\hline Weight (kg) & $39.4(11.0)$ & $42.7(9.9)$ & $46 \cdot 9(5 \cdot 3)$ & $55 \cdot 5(8 \cdot 9)$ & $58 \cdot 9(7 \cdot 3)$ \\
\hline \multirow{3}{*}{$\begin{array}{l}\text { Sum of skinfold } \\
\text { thicknesses }(\mathrm{mm}) \\
\% \text { Time with heart rate } \\
>139 \text { beats/min }\end{array}$} & & & & & \\
\hline & $21 \cdot 5(10 \cdot 2)$ & $20 \cdot 9(11 \cdot 5)$ & $20 \cdot 4(6 \cdot 8)$ & $17 \cdot 7(5 \cdot 8)$ & $19 \cdot 3(7 \cdot 5)$ \\
\hline & $6.4(3.5)$ & $6 \cdot 2(2 \cdot 4)$ & $5 \cdot 6(2 \cdot 7)$ & $5 \cdot 1(3 \cdot 4)$ & $6 \cdot 7(5 \cdot 6)$ \\
\hline \multicolumn{6}{|c|}{ Girls } \\
\hline Age (years) & $(\mathrm{n}=8)$ & $(\mathbf{n}=30)$ & $(n=32)$ & $(n=49)$ & $(n=11)$ \\
\hline $\begin{array}{l}\text { Age (years) } \\
\text { Height (m) }\end{array}$ & $11 \cdot 5(0.4)$ & $12 \cdot 1(0 \cdot 7)$ & $12 \cdot 8(1 \cdot 1)$ & $13 \cdot 6(1 \cdot 1)$ & $14 \cdot 6(0 \cdot 7)$ \\
\hline $\begin{array}{l}\text { Height (m) } \\
\text { Weight (kg) }\end{array}$ & $1.43(0.07)$ & $1.47(0.06)$ & $1.53(0.06)$ & $1.62(0.06)$ & $1 \cdot 64(0.08)$ \\
\hline \multirow{3}{*}{$\begin{array}{l}\text { Sum of skinfold } \\
\text { thicknesses }(\mathrm{mm}) \\
\% \text { Time with heart rate } \\
>139 \text { beats/min }\end{array}$} & $34 \cdot 8(5 \cdot 8)$ & $39 \cdot 4(8 \cdot 1)$ & $43 \cdot 5(5 \cdot 8)$ & $53 \cdot 0(6 \cdot 4)$ & $3 / .2(1 \cdot 4)$ \\
\hline & $25 \cdot 9(12 \cdot 6)$ & $27 \cdot 9(14 \cdot 6)$ & $23 \cdot 6(7 \cdot 0)$ & $24 \cdot 6(8 \cdot 5)$ & $30 \cdot 8(9 \cdot 2)$ \\
\hline & $5 \cdot 4(2.0)$ & $6 \cdot 0(4 \cdot 1)$ & $5 \cdot 5(3 \cdot 4)$ & $3.7(1.9)$ & $2.7(1.9)$ \\
\hline
\end{tabular}

activity, but, perhaps more importantly, it measures the relative stress placed on the cardiopulmonary system. For ease of exposition, however, we assumed that the response of the heart rate indicates the volume of physical activity.

We used a self contained, computerised telemetry system (Sport Tester 3000, Cranlea Ltd, Birmingham) to record minute by minute heart rates continuously. The system can store and replay minute by minute heart rates for up to 16 hours, and if it is interfaced with a microcomputer sustained periods with heart rates above $70 \%$ of the maximum can be readily identified and recorded. Each child was monitored from about 0900 until 2100 during a normal school day. The receivers were retrieved, replaced, and refitted the next morning, and the process was repeated over three days. Data for three school days were obtained on 163 girls and 103 boys. In addition, 92 of the boys and 120 of the girls were monitored from 0900 until 2100 on a Saturday.

\section{STATISTICAL ANALYSIS}

The data were stored and analysed with an RS1 database (BBN Software Products, Chicago). Means and standard deviations were computed, and significant differences were tested by the appropriate $t$ test or, for multiple groups, by one way analysis of variance and Scheffé analysis. Pearson product moment correlation coefficients were calculated when appropriate.

\section{Results}

Table I shows the physical characteristics of the children. The boys had heart rates $>139$ beats/min for a significantly higher percentage of time than the girls during the weekdays $(6 \cdot 2 \% v 4 \cdot 3 \%)$ and the Saturday $(5 \cdot 6 \% v 2 \cdot 6 \%)$. The relation between age and the percentage of time with a heart rate $>139$ beats $/ \mathrm{min}$ was not significant for boys, but a negative correlation with age was found for girls (weekday: $r=-0 \cdot 27$, $\mathrm{p}<0.01$; Saturday $\mathrm{r}=-0.21, \mathrm{p}<0.05$ ).

The interpretation of data on continuous heart rate is complex because the data reflect not only the metabolism of the child but also the transient emotional state, the prevailing climatic conditions, and the specific muscle groups being exercised. Although the percentage of time spent with various heart rates is of interest, the primary consideration of this study was therefore the number and length of sustained periods with a heart rate $>139$ beats/min (appropriate physical activity). Table II shows the percentage of children who had five, 10 , and 20 minute periods with heart rates $>139$ beats $/ \mathrm{min}$. The mean numbers of five, 10 , and 20 minute periods were significantly higher among boys than girls $(p<0 \cdot 01)$ during the weekdays, as were the mean numbers of five and 10 minute periods during the Saturday $(\mathrm{p}<0 \cdot 01)$. Brisk walking on a treadmill at $6 \mathrm{~km} / \mathrm{h}$ gave steady state heart rates averaging 146 beats $/ \mathrm{min}$ in these children.

Table III gives the characteristics of the children according to maturity groups. Analysis showed that the mean percentage of time with a heart rate $>139$ beats/min for girls in group 2 was significantly higher $(p<0.05)$ than that for girls in groups 4 and 5 . No significant differences in sustained periods of appropriate physical activity were detected among maturity groups in either sex.

\section{Discussion}

No other published study has used unobtrusive monitoring of the heart rate of British children for extended periods. Our results therefore provide the first objective support for the limited self reported data currently available on British children. ${ }^{56}$ Our data are 
in general agreement with the results of monitoring heart rate from other groups, ${ }^{78}$ although direct comparisons are difficult because of the different methods used and our emphasis on the importance of sustained periods of appropriate physical activity. Our results, in accord with previous findings from The Netherlands, ${ }^{910}$ suggest that girls are less physically active than similarly aged boys and that girls' level of physical activity decreases while they are at secondary school.

No significant relation was detected between the level of habitual physical activity (heart rate) and skinfold thickness in either sex. Similarly, the children classified as overweight according to the criteria of the Royal College of Physicians ${ }^{11}$ were not significantly less active than children who were not overweight.

In conclusion, we have shown that British children have surprisingly low levels of habitual physical activity and that many children seldom experience the intensity and duration of physical activity that are believed to stress the cardiopulmonary system appropriately. The pubertal stage of development or measures of body fatness, or both, do not seem to be sensitive indicators of volume of physical activity in either girls or boys. More research into the determinants of children's patterns of physical activity is required, and, in the light of our data, the effects of short periods (five minutes) of physical activity on children's cardiopulmonary systems need further investigation.

We acknowledge the technical help of Jenny Frost, Alison Husband, Pat Bond, and Clive Williams and the logistic support of Mark Palmer and Maralyn Kempson. The indexing of maturity was carried out by Dr Sarah Hannington. The work was supported by the Northcott Devon Medical Foundation and the IBM (UK) Trust.

I Simons-Morton BG, Parcel GS, O'Hara NM, Blair SN, Pate RR. Healthrelated physical fitness in childhood. Annu Rev Public Health 1988;9: 403-25.

2 Office of Population Censuses and Surveys. Census. Small area statistics. London: HMSO, 1981

3 Weiner JS, Lourie JA, eds. Practical human biology. London: Academic Press, 1981

4 Tanner JM. Growth at adolescence. 2nd ed. Oxford: Blackwell Scientific, 1962. 5 Dickenson B. The physical activity patterns of young people - the implications for PE. Bulletin of Physical Education 1986;22:36-9.

6 Williams A. Physical activity patterns among adolescents-some curriculum implications. Physical Education Review 1988;11:28-39.

7 Seliger VS, Trefny S, Bartenkova S, Pauer $M$. The habitual physical activity and fitness of 12 year old boys. Acta Paediatrica Belgica 1974;28:54-9.

8 Atomi Y, Iwaoka K, Hatta H, Miyashita M, Yamamoto Y. Daily physical acitivity levels in preadolescent boys related to $\mathrm{Vo}_{2} \max$ and lactate acitivity levels in preadolescent boys related

9 Saris WHM. Aerobic power and daily physical activity in children. Meppel, The Netherlands: Kripps Repro, 1982.

10 Verschuur R, Kemper HCG. Habitual physical activity. Medicine and Sport Science 1985;20:56-65.

11 Royal College of Physicians. Obesity. I R Coll Physicians Lond 1983;17:3-58

(Accepted 23 May 1990)
Department of Internal

Medicine I, University

Hospital Dijkzigt, 3015 GD

Rotterdam, The

Netherlands

A $\mathrm{H}$ van den Meiracker, $\mathrm{MD}$ consultant in internal medicin P J J Admiraal, MSC, research fellow

A J Man in 't Veld, $M D$, professor of cardiovascular pharmacology

F H M Derckx, MD, consultant in clinical pharmacology

H J Ritsema van Eck, MD, consultant in cardiology M A D H Schalekamp, MD, professor of internal medicine

\section{Department of}

Biostatistics, University

Hospital Dijkzigt, 3015 GD Rotterdam, The

Netherlands

P Mulder, MSC, statistician

F Hoffmann-La Roche and Co Ltd, Basle, Switzerland $P$ van Brummelen, MD, professor of pharmacology

Correspondence to: Professor M A D H Schalekamp, Department of Internal Medicine I University Hospital Dijkzigt, Room H362, Dr Molewaterplein 40, 3015 GD Rotterdam, The

Netherlands.

\title{
Prolonged blood pressure reduction by orally active renin inhibitor RO 42-5892 in essential hypertension
}

\author{
A $\mathrm{H}$ van den Meiracker, P J J Admiraal, A J Man in 't Veld, F H M Derkx, \\ H J Ritsema van Eck, P Mulder, P van Brummelen, M A D H Schalekamp
}

\section{Abstract}

Objective-To investigate the effects of a novel specific renin inhibitor, $R O$ 42-5892, with high affinity for human renin $\left(K_{i}=0.5 \times 10^{-9} \mathrm{~mol} / \mathrm{l}\right)$, on plasma renin activity and angiotensin $I I$ concentration and on 24 hour ambulatory blood pressure in essential hypertension.

Design-Exploratory study in which active treatment was preceded by placebo.

Setting-Inpatient unit of teaching hospital.

Patients - Nine men with uncomplicated essential hypertension who had a normal sodium intake.

Interventions - Two single intravenous doses of RO $42-5892(100$ and $1000 \mu \mathrm{g} / \mathrm{kg}$ in 10 minutes) given to six patients and one single oral dose $(600 \mathrm{mg})$ given to the three others as well as to three of the patients who also received the two intravenous doses.

Results-With both intravenous and oral doses renin activity fell in $\mathbf{1 0}$ minutes to undetectably low values, while angiotensin II concentration fell overall by $80-90 \%$ with intravenous dosing and by $30-40 \%$ after the oral dose. Angiotensin II concentration was back to baseline four hours after the low and six hours after the high intravenous dose and remained low for at least eight hours after the oral dose. Blood pressure fell rapidly both after low and high intravenous doses and after the oral dose and remained low for hours. With the high intravenous dose the daytime (0900-2230), night time (2300-0600), and next morning (0630-0830) systolic blood pressures were significantly $(\mathrm{p}<0.05)$ lowered by $12.5(95 \%$ confidence interval 5.6 to 19.7$), 12.2(5.4$ to 19.3$)$, and $10.7(3.2$ to 18.5$) \mathrm{mm} \mathrm{Hg}$ respectively, and daytime diastolic pressure was lowered by $9 \cdot 3(2.2$ to $16.8) \mathrm{mm} \mathrm{Hg}$. With the oral dose daytime, night time, and next morning systolic blood pressures were lowered by $10.3(5.5$ to 15.4$), 10.5(4.2$ to 17.2$)$, and 9.7 (4.0 to 15.6$) \mathrm{mm} \mathrm{Hg}$, and daytime and night time diastolic pressures were lowered by $5.8(0.9$ to 11.0$)$ and $6 \cdot 0(0 \cdot 3-12) \mathrm{mm} \mathrm{Hg}$ respectively.

Conclusions - The effect of the inhibitor on blood pressure was maintained over a longer period than its effect on angiotensin II. RO $42-5892$ is orally active and has a prolonged antihypertensive effect in patients who did not have sodium depletion. This prolonged effect seems to be independent, at least in part, of the suppession of circulating angiotensin II.

\section{Introduction}

The efficacy of drugs that interfere with the formation of the vasoconstrictor octapeptide angiotensin II is well established. Angiotensin II is formed in two steps. The decapeptide angiotensin I is generated from angiotensinogen by the proteolytic activity of the aspartyl protease renin, and then angiotensin converting enzyme converts angiotensin I to II. The beneficial results obtained with angiotensin converting enzyme inhibitors in the management of hypertension and heart failure have stimulated the search for inhibitors of renin, which is the rate limiting enzyme for the formation of plasma angiotensin II.

Detailed knowledge of the tertiary structure of renin has led to the recent advent of high affinity inhibitors specific for renin. These inhibitors, when given intravenously to normotensive subjects, effectively reduce plasma renin activity and angiotensin II..$^{1-5}$ Two such compounds have been shown to lower blood pressure, but this effect was short lived. ${ }^{12}$ RO $42-5892$ is a novel renin substrate analogue with high affinity for human 